\title{
Escuela pública
}

\section{Public school}

Hay varias razones por las cuales la escuela pública es importante para una sociedad. Una de ellas es que, bien diseñada y gestiona$\mathrm{da}$, es un espacio de socialización entre diferentes grupos, con posibilidad de atender la riqueza de naciones como la mexicana, con sus diferencias étnicas, de género, sexuales, culturales, etarias, por señalar algunas. Otra es que posibilita la cohesión social, ya que a ellas asistiría alumnado de diferentes estratos sociales. La mezcla de las diferencias de las niñas, niños y adolescentes es realmente importante para lograr una sociedad más democrática, pero también personas más empáticas y tendientes a una ética del cuidado.

Un sistema educativo con escuelas buenas para alumnado proveniente de familias ricas y de baja calidad para los pobres es nocivo para la sociedad. Al permitir que el dinero sea el determinante de aprendizaje (bien por la dicotomía escuela buena para los que la paguen, escuelas no buenas para el resto, o bien porque no se logra romper el determinismo social con que la pobreza asedia a la educación), el sistema es intrínsecamente excluyente. En las economías emergentes, una mayor cantidad de población está accediendo a ingresos más altos y con ello empiezan a vaciar los espacios públicos (entre ellos las escuelas), pues las sociedades de mercado envían el doble mensaje de que "los espacios privados son mejores" y que los "espacios públicos son deficientes". En educación esto último se aprecia con la ola de propaganda de toda índole (noticiosa, "espectaculares", radial, televisiva) que difunde el mensaje de que la escuela pública es de mala calidad, que sus maestros y maestras no trabajan, que los actores escolares no cumplen con su responsabilidad de que los y las alumnas aprendan

Para superar las deficiencias en el aprendizaje para todas y todos es preciso que el sistema educativo se gestione desde dos perspectivas simultaneas: la inclusión y la equidad. 
La vía de la inclusión busca lograr que estemos atentos a todos los actos de exclusión, tanto como a generar estrategias para atender las diversidades. Hay diversidades que son atendidas de cierta manera, como son las de necesidades educativas especiales (problemas de aprendizaje o alumnado con capacidades superiores). Hay otras que tienden a hacer lo propio como la educación indígena o la educación intercultural y bilingüe. Pero hay otras que no aparecen en nuestro horizonte de inclusión como en el tema de la igualdad de género, tanto desde la mirada femenina como desde las nuevas masculinidades.

La vía de la equidad busca que existan acciones efectivas que compensen las desigualdades sociales, políticas, económicas entre las poblaciones. Es dar más a quien más lo necesita. Son acciones afirmativas que tienden a nivelar las disparidades suscitadas en otras esferas sociales. Es procurar que las poblaciones más pobres y desprovistas de servicios públicos tengan acceso a ellos, de tal manera que los tengan disponibles y asequibles. Es poner ambientes para que el alumnado de zonas marginadas (urbanas y rurales) pueda tener condiciones de muy buena calidad: profesores y profesoras, infraestructura y dotación de materiales educativos, entre otros.

Las medidas que desde la Secretaría de Educación Pública (SEP) se han dado durante este primer trimestre de 2016 nos indican que hay una propensión hacia el apoyo a las escuelas públicas, pero tiende a ser diseñado para las escuelas urbanas, dejando de lado a muchas otras públicas rurales, como las multigrado y los centros comunitarios del Consejo Nacional de Fomento Educativo (CONAFE).

El desafío es tener escuelas de tan buena calidad y tan atractivas, que ricos y pobres quieran estudiar en ellas. En este desafío hay que ir con sumo cuidado respecto a la provisión y prestación del servicio, si es que la educación pública verdaderamente habrá de fortalecer el tejido social y la creación de comunidades, el aprendizaje de la convivencia, de la cooperación y del cuidado recíproco. 